\title{
The phylogenetic position of Acoela as revealed by the complete mitochondrial genome of Symsagittifera roscoffensis
}

\author{
Adina Mwinyi ${ }^{1}$, Xavier Bailly ${ }^{2}$, Sarah J Bourlat ${ }^{3}$, Ulf Jondelius ${ }^{3}$, D Timothy J Littlewood ${ }^{4}$, Lars Podsiadlowski ${ }^{*}$
}

\begin{abstract}
Background: Acoels are simply organized unsegmented worms, lacking hindgut and anus. Several publications over recent years challenge the long-held view that acoels are early offshoots of the flatworms. Instead a basal position as sister group to all other bilaterian animals was suggested, mainly based on molecular evidence. This led to the view that features of acoels might reflect those of the last common ancestor of Bilateria, and resulted in several evo-devo studies trying to interpret bilaterian evolution using acoels as a proxy model for the "Urbilateria".

Results: We describe the first complete mitochondrial genome sequence of a member of the Acoela, Symsagittifera roscoffensis. Gene content and circular organization of the mitochondrial genome does not significantly differ from other bilaterian animals. However, gene order shows no similarity to any other mitochondrial genome within the Metazoa. Phylogenetic analyses of concatenated alignments of amino acid sequences from protein coding genes support a position of Acoela and Nemertodermatida as the sister group to all other Bilateria. Our data provided no support for a sister group relationship between Xenoturbellida and Acoela or Acoelomorpha. The phylogenetic position of Xenoturbella bocki as sister group to or part of the deuterostomes was also unstable.

Conclusions: Our phylogenetic analysis supports the view that acoels and nemertodermatids are the earliest divergent extant lineage of Bilateria. As such they remain a valid source for seeking primitive characters present in the last common ancestor of Bilateria. Gene order of mitochondrial genomes seems to be very variable among Acoela and Nemertodermatida and the groundplan for the metazoan mitochondrial genome remains elusive. More data are needed to interpret mitochondrial genome evolution at the base of Bilateria.
\end{abstract}

\section{Background}

Acoels are marine, soft-bodied, unsegmented worms without hindgut and anus - the mouth opens to a central digestive parenchyma, a gut lumen is absent. Acoels move with their multiciliated epidermis although many are 'surprisingly muscular' [1]. Most of the species are free-living, some are ectocommensals. Several species from the subtaxa Sagittiferidae and Convolutidae form obligate symbioses with green algae [2], making them functional photoautotroph organisms. In traditional systematics the Acoela were considered to be representatives of the Platyhelminthes, due to their 'flatworm-like'

\footnotetext{
* Correspondence: lars@podsiadlowski.de

'Department of Evolutionary Biology and Ecology, University of Bonn, An der Immenburg 1, 53121 Bonn, Germany

Full list of author information is available at the end of the article
}

features such as the ciliated epidermis, the frontal organ, neoblasts, hermaphroditic reproduction, biflagellate sperm, and a lack of body cavities (acoelomate structure), hindgut and anus $[3,4]$. Based on the ultrastructural characteristics of cilia, and the hypothesized reduction of gut and protonephridia, Ehlers (1985) combined Acoela with Nemertodermatida to form the Acoelomorpha. In his system the Catenulida form the sister group to all other Platyhelminthes (Euplatyhelminthes), which comprise the sister groups Acoelomorpha and Rhabditophora. However, the monophyly of the Platyhelminthes was soon questioned because of the weakness of these morphological characters [5,6]. Subsequent ultrastructural studies have demonstrated numerous differences between Acoelomorpha and Platyhelminthes, particularly amongst characters once thought to be 
homologous. For example, frontal organ morphology $[6,7]$, sperm ultrastructure [8], and patterns in the nervous and muscular systems [9-11] all demonstrate the uniqueness of acoelomorphs.

Early molecular systematic studies using ribosomal RNA genes strongly suggested that Acoela and Nemertodermatida were distinctly separate from the Platyhelminthes [12-14]; this result remains coherent even in the light of more taxa, more sequence data and more sophisticated models of phylogenetic analysis [15]. In the last 10 years several phylogenetic studies with molecular sequences have suggested a phylogenetic position of acoels as sister group to all other Bilateria [16-19]. Studies with broad taxon sampling of both Acoela and Nemertodermatida supported paraphyly of Acoelomorpha, with Acoela forming the sister group to the remaining Bilateria (Nemertodermatida + Nephrozoa) [19-21]. Presuming a position as sister group to all other Bilateria and considering the comparably simple body organisation, the morphological features of acoels may provide insights concerning the bodyplan of the "last common bilaterian ancestor' [18], the ancestor of extant acoels, protostomes and deuterostomes [22]. Thus, acoels came into the focus of studies in evolutionary developmental biology as a possible window into the deep past of bilaterians [23-27].

In spite of these advances there is still controversy about the phylogenetic position of Acoela, and at the same time Nemertodermatida. Despite overwhelming molecular evidence against a platyhelminth affinity, some authors discuss the stem cell system of Acoela and Rhabditophora as a potential synapomorphy of these taxa [28]. However, data about stem cells from other invertebrate taxa are very sparse, so this character is in need of a broad comparative study. Recent phylogenomic studies do not recover platyhelminth affinities for Acoela, but show quite different results due to the varying amount of genes and taxa covered. A phylogenomic analysis of EST data from Isodiametra pulchra [29] found no relevant nodal support for any sister group relation. However, the best tree from this analysis clustered I. pulchra together with the deuterostomes. Another EST study, including the acoel species Neochildia fusca and S. roscoffensis also failed to support any convincing relationship with another metazoan phylum or lineage [30]. Thus, the authors omitted acoels from subsequent analyses due to their low leaf stability. Finally, a recent increase in taxon sampling incorporated in the latter study, with additional sampling of acoels and including nemertodermatids, supported Acoelomorpha (Acoela + Nemertodermatida) as a monophylum with bootstrap support of $70 \%$ and $90 \%$ in two datasets of different sizes [31]. Acoelomorpha were the sister group to Xenoturbella in that study, but with only moderate bootstrap support from one of the two analysed datasets. Xenoturbella and Acoelomorpha together formed the sister group to all other Bilateria (= Nephrozoa), once again with merely moderate nodal support.

To evaluate the phylogenetic position of acoels using an independent set of molecular data we present the first complete sequence of a mitochondrial genome of a member of the Acoela, Symsagittifera roscoffensis (Graff, 1891). We describe gene content and tRNA secondary structure, compare the mitochondrial gene order to other taxa and show the results of a phylogenetic analysis with sequence alignments from mitochondrial protein-coding genes.

\section{Results and discussion}

\section{Organisation of the genome and genes}

The circular, double-stranded mitochondrial genome of S. roscoffensis consists of 14803 bp (Fig. 1, table 1). It contains two rRNA- and twelve protein-coding genes. The gene for atp8, which is normally also present in bilaterian $\mathrm{mt}$ genomes, is missing. This gene is also absent in the mitochondrial genomes of Platyhelminthes, Chaetognatha and almost all nematodes (except Trichinella spiralis). Thus there seems to be a tendency to lose atp 8 in several unrelated taxa. We identified 20 tRNA genes and determined their putative secondary structures (Fig. 2). Despite a careful software search and inspection by eye, no sequence resembling the genes for trnL1 and trnL2 could be detected except within other genes. Two candidate positions for $\operatorname{trnL} 1$ and $\operatorname{trnL2}$ are in nad5 (5778-5841; reverse direction) and in $r r n L$ (8131-8201), respectively (Fig. 2). Amongst the tRNA genes, one loop of the typical cloverleaf structure is absent in some cases: trnS1 and trnD lack the DHUstem. A missing DHU- stem in trnS1 is typical for all parasitic flatworms and many other Metazoa [32,33]. The T $\psi C$-stem is missing in trnA, $-H,-I,-M,-T,-E$ and $-Y$. The majority of the tRNA genes show either mismatches of one to several nucleotides and/or shortened stems and enlarged loops, respectively (Fig. 2). Mitochondrial genes are transcribed from both strands, with cox1-3, atp6, $\operatorname{lr} R N A$, srRNA, nad6 and nad4, as well as $\operatorname{trn} T,-F,-Y,-V,-N,-H,-E,-K,-A,-R,-G,-S 1,-S 2$ and $-M$ being transcribed from the plus-strand, the remaining ones from the minus-strand. Thirty, mostly short, non-coding regions can be found, ranging from one to $137 \mathrm{bp}$ in length. None of these regions is significantly more AT-rich compared to the complete genome. Thus, a putative control region [34] could not easily be determined at first sight. The entire genome has a high $\mathrm{A}+\mathrm{T}$ content of $75.3 \%$ and overall nucleotide frequencies of $38.6 \% \mathrm{~A}, 36.7 \% \mathrm{~T}, 12.8 \% \mathrm{G}$ and $11.9 \% \mathrm{C}$. AT-skew $[(\mathrm{A}-\mathrm{T}) /(\mathrm{A}+\mathrm{T})]$ - and GC-skew $[(\mathrm{G}-\mathrm{C}) /(\mathrm{G}+\mathrm{C})][35]$ of the whole plus-strand sequence are both close to zero (AT: 


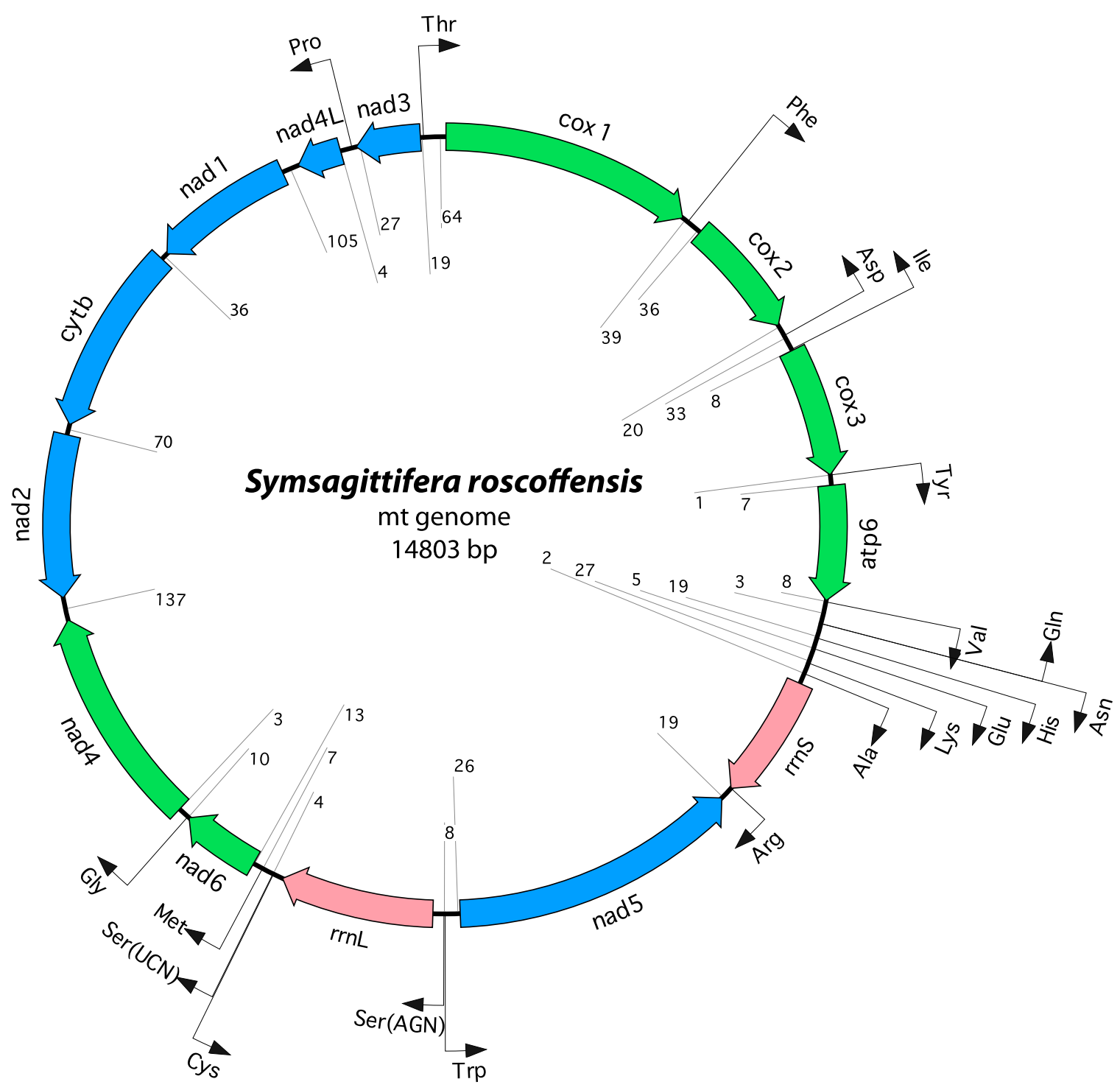

Figure 1 Mitochondrial DNA map of S. roscoffensis [GenBank: HM237350]. Gene abbreviations are explained in the text. Numbers show the size of non-coding regions between genes. Protein-coding genes on plus-strand are coloured in green, on minus-strand in blue and ribosomal RNA genes are in red. tRNA genes are black arrows, specified by the three letter abbreviation of the corresponding amino acid.

0.02; GC: 0.05$)$, so there is no conspicuous strandasymmetry in nucleotide frequency as in many other metazoan mt genomes [36]. High A+T content is a typical feature of nuclear ribosomal genes of Acoela, and it has been suggested a possible factor affecting phylogenetic resolution of these worms amongst the Metazoa [15], similarly to the acoels' highly truncated and modified rRNA genes.

Overlaps between genes were not detected, except for the remaining possibility that $\operatorname{trn} L 1$ and $\operatorname{trn} L 2$ are positioned within nad5 and $r r n L$, respectively. All protein genes terminate with the codon TAA, except for cox3 ending with TAG. Existing start codons are more variable: ATT is found in $c y t b, n a d 3, \operatorname{cox} 2$ and cox3; nad1 and nad4 start with ATG; atp 6 begins with ATA and nad6 with ATC. Only cox 1 with GGT and nad2 with CAT are exceptions from the commonly used start codons in mitochondrial genomes. Another uncommon feature is a repeat region of $42 \mathrm{bp}$ found in nad6 (5' TGA GAA ATT TAC AAT CAA ATT TTA ACT ATT TCT CCT AGA TTT 3').

\section{Gene order}

The gene order found in S. roscoffensis shows no clear similarity with any other mitochondrial gene order published to date. Fig. 3 shows a comparison between 
Table 1 Mitochondrial genome organisation of Symsagittifera roscoffensis

\begin{tabular}{|c|c|c|c|c|c|c|c|}
\hline Gene & Strand & $\begin{array}{r}\text { Position } \\
\text { (start - end) }\end{array}$ & Length (nuc.) & GC-/AT- skew & Start- codon & Stop- codon & Intergenic bp \\
\hline $\operatorname{cox} 1$ & + & $1-1551$ & 1551 & $0.09 /-0.16$ & GGT & TAA & 39 \\
\hline $\operatorname{trnF}$ & + & $1591-1651$ & 61 & & & & 36 \\
\hline $\cos 2$ & + & $1688-2428$ & 741 & $0.08 /-0.02$ & ATT & TAA & 20 \\
\hline $\operatorname{trn} D$ & - & $2449-2499$ & 51 & & & & 33 \\
\hline $\operatorname{trnl}$ & - & $2533-2594$ & 62 & & & & 8 \\
\hline $\cos 3$ & + & $2603-3394$ & 792 & $0.17 /-0.2$ & ATT & TAG & 1 \\
\hline $\operatorname{trn} Y$ & + & $3396-3451$ & 56 & & & & 7 \\
\hline atp6 & + & $3459-4160$ & 702 & $0.04 /-0.2$ & ATA & TAA & 8 \\
\hline $\operatorname{trnV}$ & + & $4169-4237$ & 69 & & & & 3 \\
\hline $\operatorname{trn} Q$ & - & $4241-4303$ & 63 & & & & 0 \\
\hline $\operatorname{trn} N$ & + & $4304-4375$ & 72 & & & & 19 \\
\hline $\operatorname{trnH}$ & + & $4395-4456$ & 62 & & & & 5 \\
\hline $\operatorname{trn} E$ & + & $4462-4527$ & 66 & & & & 27 \\
\hline $\operatorname{trnK}$ & + & $4555-4621$ & 67 & & & & 2 \\
\hline $\operatorname{trn} A$ & + & $4624-4688$ & 65 & & & & 0 \\
\hline $\operatorname{rrnS}(12 S)$ & + & $4689-5452$ & 764 & $0.08 / 0.14$ & & & 0 \\
\hline $\operatorname{trn} R$ & + & $5453-5514$ & 62 & & & & 19 \\
\hline nad5 & - & $5534-7309$ & 1776 & $0.05 /-0.15$ & ATT & TAA & 26 \\
\hline $\operatorname{trn} W$ & - & $7336-7400$ & 65 & & & & 8 \\
\hline trnS-AGY & + & $7409-7475$ & 67 & & & & 0 \\
\hline$r r n L(16 S)$ & + & $7476-8417$ & 942 & $0.27 / 0.1$ & & & 0 \\
\hline $\operatorname{trn} C$ & - & $8418-8478$ & 61 & & & & 4 \\
\hline $\operatorname{trnS}$-UCN & + & $8483-8546$ & 64 & & & & 7 \\
\hline $\operatorname{trnM}$ & + & $8554-8602$ & 49 & & & & 13 \\
\hline nad6 & + & $8616-9095$ & 480 & $0.01 /-0.17$ & ATC & TAA & 10 \\
\hline $\operatorname{trn} G$ & + & $9106-9170$ & 65 & & & & 3 \\
\hline nad4 & + & $9174-10523$ & 1350 & $0.12 /-0.21$ & ATG & TAA & 137 \\
\hline nad2 & - & $10661-11650$ & 990 & $-0.07 /-0.19$ & CAT & TAA & 70 \\
\hline cytb & - & $11721-12881$ & 1161 & $0.03 /-0.24$ & ATT & TAA & 36 \\
\hline nad1 & - & $12918-13787$ & 870 & $0.18 /-0.25$ & ATG & TAA & 105 \\
\hline nad4L & - & $13893-14162$ & 270 & $0.11 /-0.07$ & ATG & TAA & 4 \\
\hline $\operatorname{trn} P$ & - & $14167-14234$ & 68 & & & & 27 \\
\hline nad3 & - & $14262-14654$ & 393 & $0.14 /-0.21$ & ATT & TAA & 19 \\
\hline $\operatorname{trnT}$ & + & $14674-14739$ & 66 & & & & 66 \\
\hline
\end{tabular}

The whole molecule consists of $14803 \mathrm{nt}$; exact gene loci and the number of intergenic base pairs are depicted.

S. roscoffensis, Paratomella rubra, Nemertoderma westbladi and Microstomum lineare [17], Fasciola hepatica [37], Xenoturbella bocki [38-40], and the putative bilaterian ground pattern [41]. Even the partial genome of P. rubra [17], another member of the Acoela, differs completely from our data. Both organisms share merely the fact that $r r n S$ and $r r n L$ are not adjacent, but separated by one (S. roscoffensis) and four (P. rubra) proteinencoding genes, respectively. This feature was also found in the nemertodermatid species Nemertoderma westbladi [17]. The ancestral state is supposed to be a separation only by $\operatorname{trn} V$ [41], a feature found in many metazoan mitochondrial genomes. Conserved gene blocks, which are shared with other taxa, could not be identified in S. roscoffensis. In addition to visual comparison of genome maps, we analyzed gene order data with CREx [42], determining the number of common intervals. This means the number of "blocks" with the same set of genes, regardless of their order inside a "block". We compared only gene orders of protein-coding and ribosomal RNA genes, as tRNAs are known to be subject to more frequent gene translocation than the larger genes. The result (Additional file 1, Fig. S1) shows overall low numbers of common intervals for comparison of S. roscoffensis with any of the other gene orders (0-18, whereas the maximum number of possible common intervals is 176). However, although not significant, the highest numbers (16-18) are obtained in comparison 


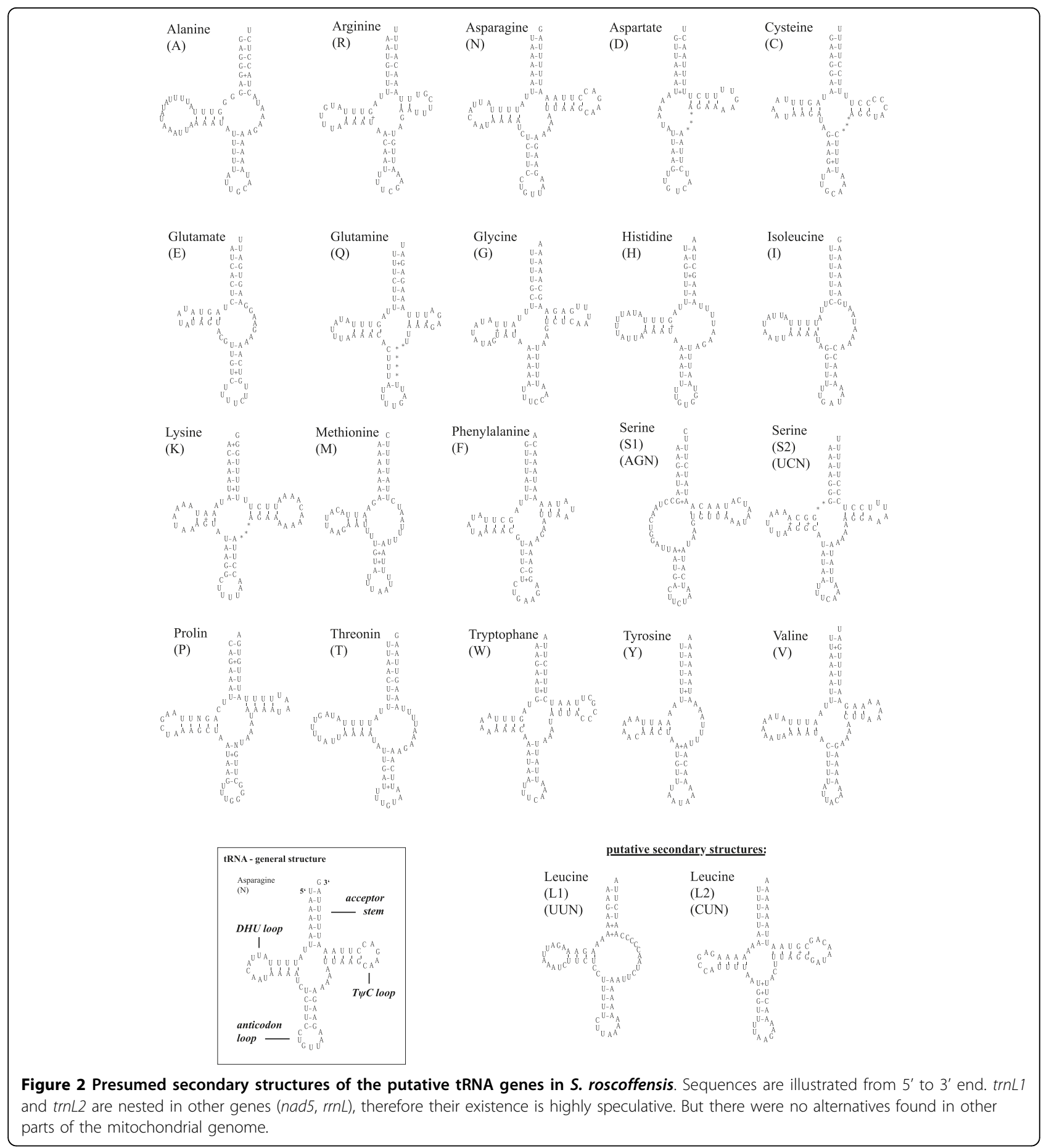

with the putative deuterostome ground pattern and with Xenoturbella bocki (which differ only by the relative position of nad6), while the lowest number was obtained in comparisons to platyhelminth gene orders (Fasciola: 2, Schistosoma: 0). We also determined breakpoint distances between these taxa, but these results were even less meaningful for $S$. roscoffensis (Additional file 1, Fig. S1).

\section{Phylogenetic analysis}

Initial Maximum Likelihood (ML) and Bayesian Inference (BI) analyses with evolutionary models using site-homogenous substitution matrices derived from mitochondrial amino acid alignments (mtREV, mtZOA), yielded poor resolution of the phylogenetic position of acoels. It is well known that analyses of mitochondrial amino acid alignments on higher taxonomic levels suffer 


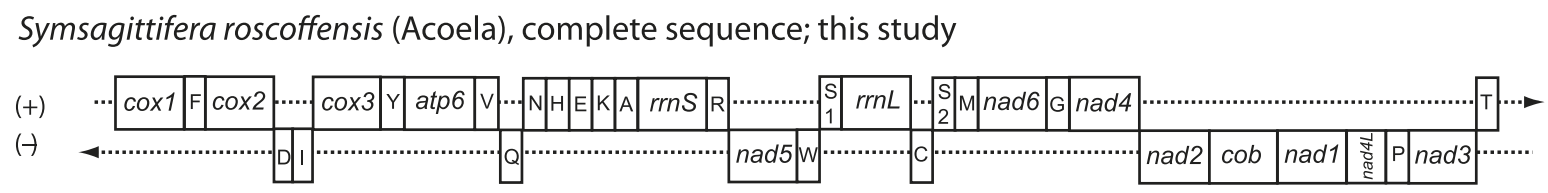

Paratomella rubra (Acoela), partial sequence; Ruiz-Trillo et al., 2004

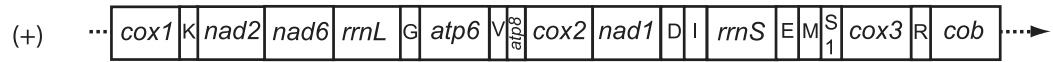

$\rightarrow$

Nemertoderma westbladi (Nemertodermatida), partial sequence; Ruiz-Trillo et al., 2004

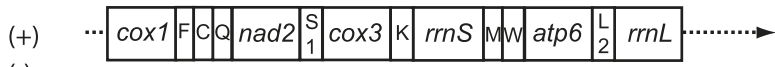

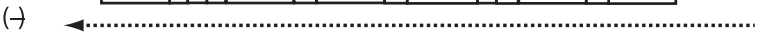

Microstomum lineare (Rhabditophora), partial sequence; Ruiz-Trillo et al., 2004

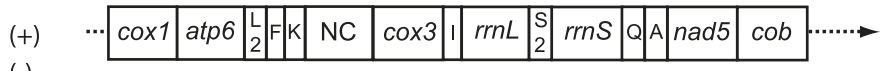

$(\rightarrow$

putative bilaterian ground pattern, complete sequence; Lavrov and Lang, 2005

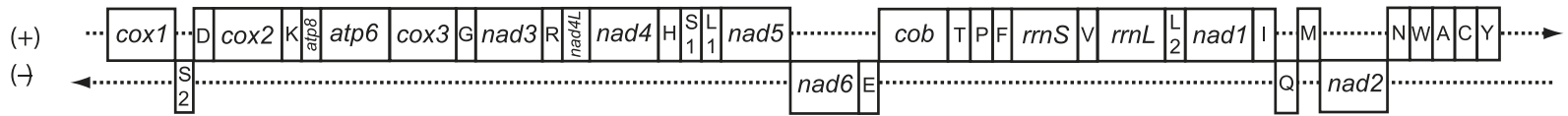

Fasciola hepatica (Trematoda), complete sequence; Le et al., 2003

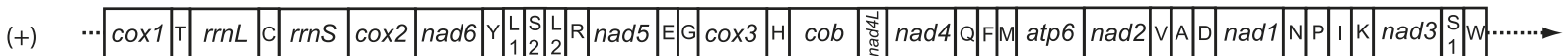

$(\rightarrow$

(1)

Xenoturbella bocki (Deuterostomia), complete sequence; Bourlat et al, 2006, 2009

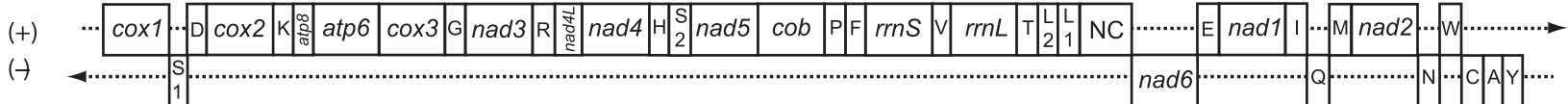

Figure 3 Gene order comparison. Gene order of S. roscoffensis compared to the partial sequences of Paratomella rubra (Acoela), Nemertoderma westbladi (Nemertodermatida) and Microstomum lineare (Rhabditophora), as well as to the complete sequence of Fasciola hepatica (Trematoda), Xenoturbella bocki (Xenoturbellida) and the putative bilaterian ground pattern.

from two major problems: (a) the taxa may strongly vary in amino acid composition, which hampers the usefulness of a fixed substitution matrix, and (b) accelerated substitution rates in some fast-evolving taxa, leading to long-branch attraction artifacts. A few recent approaches aim to handle these problems more appropriately. In large datasets the empirical site- heterogeneous CAT mixture model [43] is superior to all site-homogenous amino acid matrix models in avoiding long-branch attraction [44]. In addition, changes in model parameters for parts of the tree will be applied empirically using the "breakpoint" (BP) approach in combination with the CAT model [45]. A recent study demonstrated the usefulness of the CAT-BP model by 
placing the long-branching Tunicata together with Acrania and Vertebrata as Chordata, while other model settings were not successful in this respect [46]. We set up a dataset of 50 species, including representative members of all phyla, among them long-branching taxa like Platyhelminthes and Nematoda. We ran four MCMC chains with NH-PhyloBayes and the CAT-BP option. Two chains converged with each other twice, each favoring different topologies with respect to acoels. In both variants Acoela and Nemertodermatida were supported as sister groups, with significant support values (Bayesian posterior probabilities equal or above 0.95). The first topology, recovered from two out of four independent chains (Fig. 4) shows significant support (1.0) for Acoela and Nemertodermatida forming the sister group to all other Bilateria (0.95). Ecdysozoa excluding nematodes (1.0) as well as Lophotrochozoa + Nematoda + Chaetognatha (1.0) and Deuterostomia + Xenoturbella (1.0) are significantly supported.

The other topology, with small differences represented in the two other chains, found no resolution at the base of Bilateria (Fig. 5). Instead there is a polytomy of five taxa: Xenoturbella, Acoela + Nemertodermatida, Ambulacraria, Chordata and the protostomes. In the best tree Xenoturbella clusters with Acoela + Nemertodermatida, but there is no significant support for this group $(0.76$ and 0.92 , respectively).

Due to these findings and the preliminary analyses we suspected that it was predominantly Xenoturbella which had an unstable position in the phylogenetic trees. Therefore we conducted additional analyses with a dataset without Xenoturbella, and a second analysis without Acoela and Nemertodermatida. In both variants four independent chains were run. In all four chains with Xenoturbella omitted, Acoela and Nemertodermatida form a monophylum which is the sister group to the remaining Bilateria (with significant support in three of the four chains; additional file 1, Fig. S2). In the analysis without Acoela and Nemertodermatida, Xenoturbella was found either as sister to Deuterostomia (with support values of 0.65 and 0.99 ) or as sister to Ambulacraria (with support values of 0.87 and 1.0)(Additional file 1, Fig. S3). Thus, in the absence of acoels Xenoturbella has a more unstable position in the bilaterian tree than acoels have in the absence of Xenoturbella. Acoels remain a critically important taxon to place within the Metazoa.

\section{Conclusions}

\section{Concluding discussion}

Mitochondrial gene order of the complete mitochondrial genome of the acoel S. roscoffensis is highly divergent from that of other bilaterian animals, including the partial mitochondrial genome of Paratomella rubra. Even computational approaches of gene order comparison like minimal breakpoint analysis and common interval analysis did not favour any affinity of $S$. roscoffensis to another taxon. Phylogenetic analyses of mitochondrial amino acid sequences give support for acoels forming a clade with nemertodermatids. But the limited available dataset representing the Nemertodermatida gives this result a rather preliminary nature. The dataset of Nemertoderma westbladi is incomplete as it consists of sequences from only three complete and two partial genes, thus covering only $34.8 \%$ of the final alignment. For a better evaluation of monophyly versus paraphyly of Acoelomorpha we are in need of more complete mitochondrial genome sequences from Nemertodermatida and Acoela.

Altogether we see more evidence for a position of Acoela and Nemertodermatida branching off early from the bilaterian tree rather than being grouped with deuterostomes or protostomes. The position of Xenoturbella cannot be fixed with this dataset, but its affinity to deuterostomes is greater than to Acoela and/or Nemertoderma.

Our trees also demonstrate limitations of the CAT-BP model with the bilaterian mitochondrial protein dataset. Nematoda are still clustering with the similarly longbranched Platyhelminthes and Syndermata, instead of forming a monophylum with other ecdysozoans (in this case arthropods, a priapulid and an onychophoran). Almost all other molecular datasets support Ecdyszoa (including Nematoda), so this must be an artifact probably due to selection. A similar problem is described from snakes, where selection seems to act on mitochondrial protein-complexes under special physiological conditions [47]. The long branches in the bilaterian tree are found in both parasitic and in free-living species of nematodes and platyhelminths. Thus, a parasitic life style does not seem to contribute to this accelerated evolutionary change.

If Acoela and Nemertodermatida represent ancient clades which split off early from the bilaterian tree, while Xenoturbella splits off later than these two, probably as sister group of the deuterostomes [38,40], then we can easily interpret morphological features shared by both as plesiomorphic character states, shared with the last common ancestor of Bilateria. As Telford [48] noted, Acoela and Xenoturbella share the following features: an acoelomate bodyplan with ventral mouth and absence of anus [1]; a unique tapering shelf at the ciliary tip and other similarities in the ciliary rootlets [49]; the nervous system is non-centralized and intra-epidermal in some Acoela and in Xenoturbella [50]. Recently, Nielsen [51] pointed out that the genomes of Xenoturbella and acoels have a significantly reduced Hox gene complement $[25,26,52]$. The more complex set of hox 


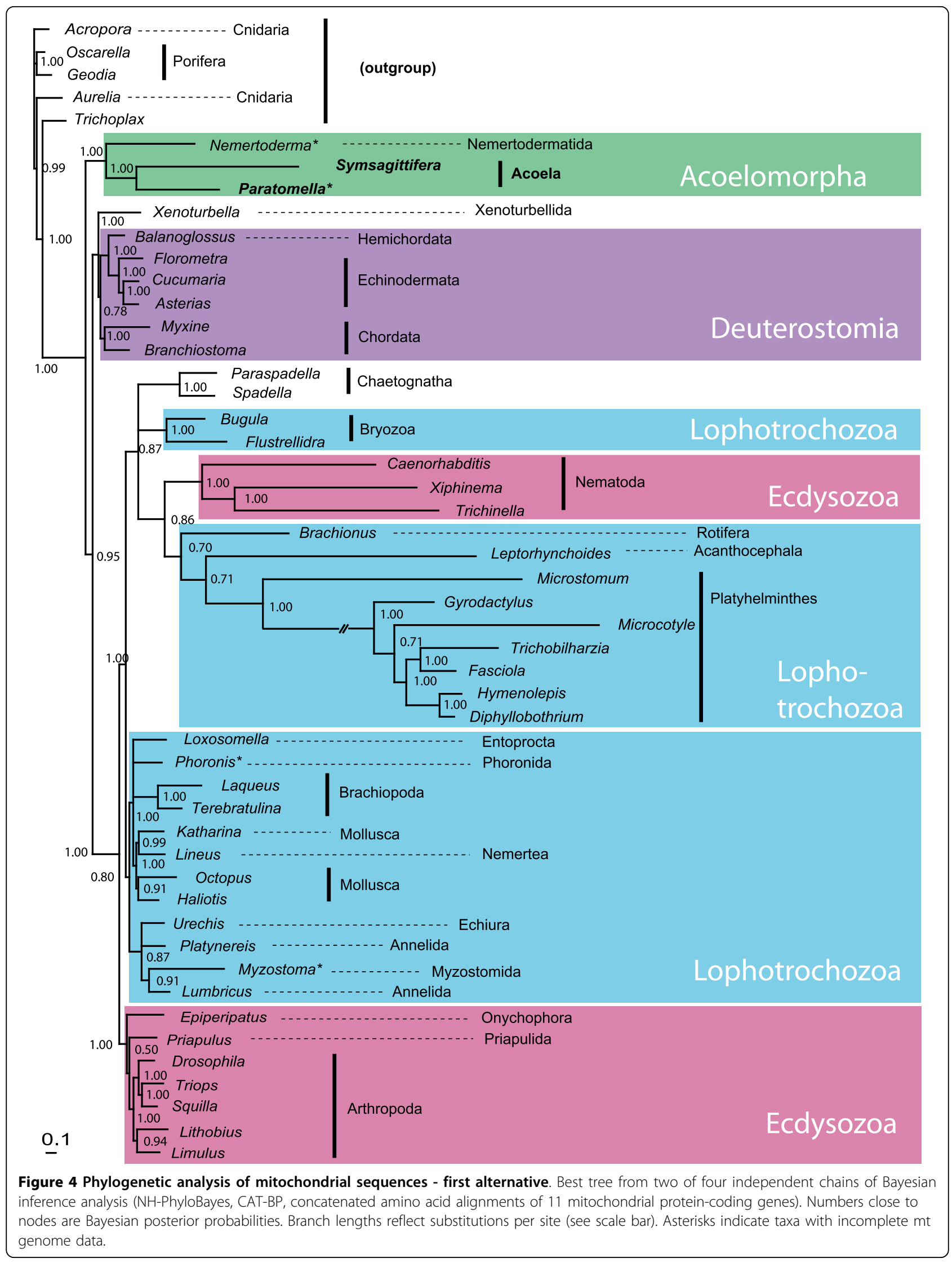




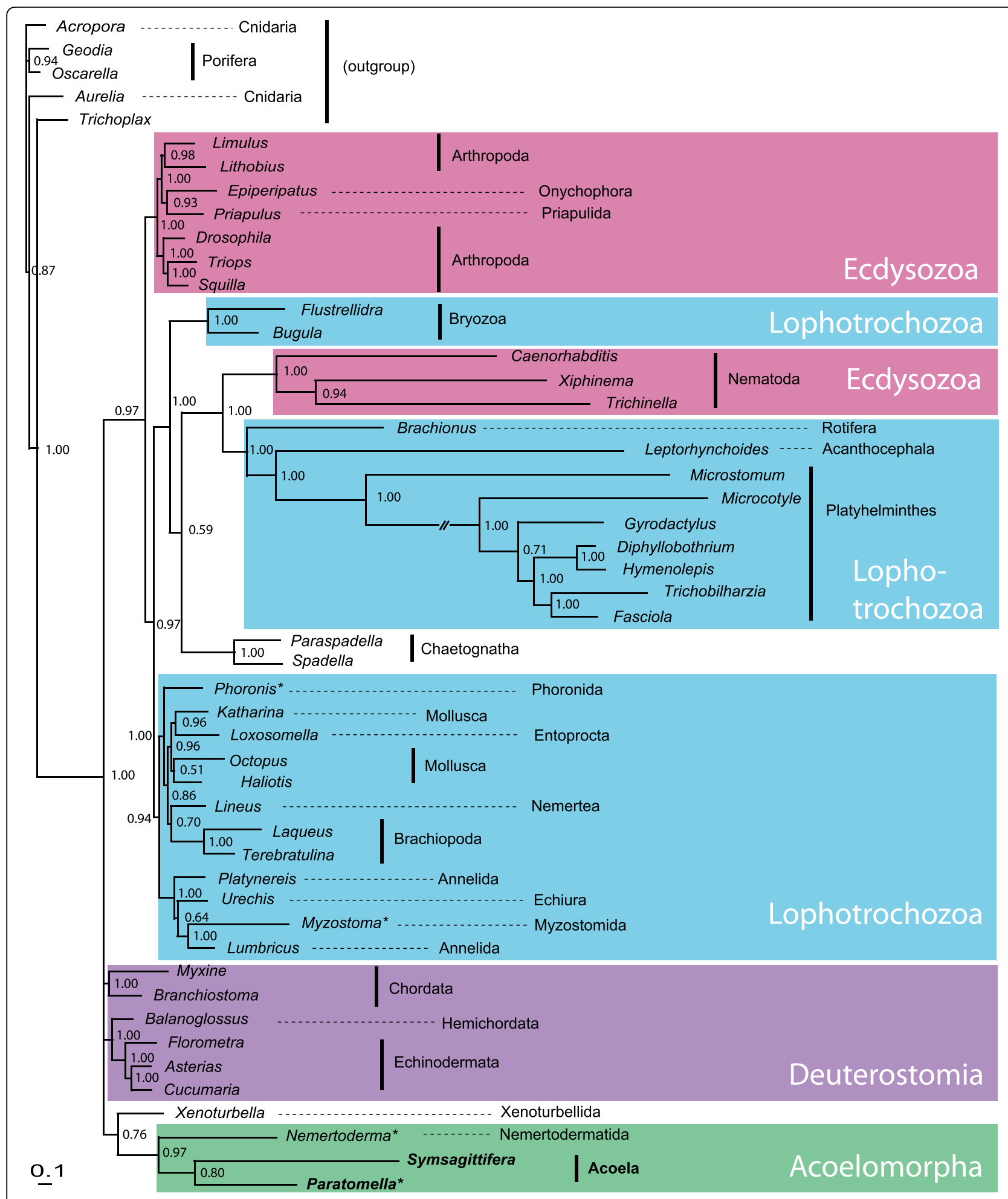

Figure 5 Phylogenetic analysis of mitochondrial sequences - second alternative. Alternative tree topology from one of four independent chains of Bayesian inference analysis (NH-PhyloBayes, CAT-BP, concatenated amino acid alignments of 11 mitochondrial protein-coding genes). Numbers close to nodes are Bayesian posterior probabilities. Branch lengths reflect substitutions per site (see scale bar). Asterisks indicate taxa with incomplete mt genome data. 
genes in the remaining bilaterians would be a valuable apomorphic character supporting Nephrozoa excl. Xenoturbella, a topology as in Fig. 5 (noting that there is only insufficient data from Nemertodermatida).

But this plesiomorphic feature cannot support a relationship between Xenoturbella and acoels. If Xenoturbella is part of the deuterostomes (as suggested by the tree in Fig. 4), the hox complement of Xenoturbella must be secondarily reduced, as there are many similarities in the hox complement of the remaining deuterostome and protostome taxa. Nuclear genome data of the complete hox clusters seem to be indispensible for a comprehensive evaluation of the evolution of hox genes at the base of Bilateria.

With regard to comparative analysis of mitochondrial genomes, especially gene order, more data are definitely needed, e.g. complete mitochondrial genome sequences from more than one acoel species, since the comparison of $S$. roscoffensis and P. rubra has shown that gene order in acoels seem to differ radically. Thus, single "representative" species are by no means sufficient to characterise or represent taxa [53]. Similarly, nemertodermatid genomes also require further and exhaustive evaluations. There is still no complete mitochondrial sequence of this group available, preventing meaningful, genomebased phylogenetic analyses.

\section{Methods}

\section{Specimen, DNA extraction, PCR and cloning}

$S$. roscoffensis specimens were provided by Xavier Bailly and were sampled close to the Station Biologique de Roscoff (France). All analyses were conducted with individuals preserved in $100 \%$ ethanol. DNA was isolated from whole animals (approx. 15-20 specimens per approach) using the DNeasy Blood \& Tissue 50 kit (Qiagen, Germany) and following the manufacturer's guidelines. Based on previously published primers for cox1 [54], cytb [55] and $r r n L$ [56] initial genome fragments were amplified and provided the basis for specific primer design. Additional primary sequence information came from the EST sets provided by the
NCBI nucleotide database and NCBI trace archive. Primer suitability for both amplification and sequencing was checked with the NetPrimer tool (Premier Biosoft int.). Primer sequences and annealing temperatures are given in table 2. General PCR setup was done in $50 \mu \mathrm{l}$ volumes $(41.75 \mu \mathrm{l}$ water, $5 \mu \mathrm{l} 10 \times$ buffer, $0.25 \mu \mathrm{l} \mathrm{Taq}$ polymerase $(5 \mathrm{U} / \mu \mathrm{l}), 1 \mathrm{ml} \mathrm{dNTP}$ mixture, $1 \mu \mathrm{l}$ template DNA, $1 \mu \mathrm{l}$ primer mixture $(10 \mu \mathrm{M}$ each $))$. PCR conditions were: $94^{\circ} \mathrm{C}$ for $2 \mathrm{~min}, 40$ cycles of $94^{\circ} \mathrm{C}$ for $30 \mathrm{sec}$, primer-specific annealing temperature for 1 min, $68^{\circ} \mathrm{C}$ for $1 \mathrm{~min}$ and a final extension step of $68^{\circ} \mathrm{C}$ for $2 \mathrm{~min}$. For standard PCR up to $3 \mathrm{~kb}$ we used the Eppendorf 5-prime Taq polymerase and buffer (5-prime, Germany). When we expected large PCR fragments we used the Takara LA kit and set up PCRs in $25 \mu \mathrm{l}$ volumes $(16.75 \mu \mathrm{l}$ water, $2.5 \mu \mathrm{l}$ buffer, $0.25 \mu \mathrm{l}$ Takara LA Taq polymerase, $4 \mu \mathrm{l}$ dNTP mixture, $1 \mu \mathrm{l}$ template DNA, $0.5 \mu \mathrm{l}$ primer mixture $(10 \mu \mathrm{M}$ each $))$. In this case conditions were as above except for the extension step of $72^{\circ} \mathrm{C}$ for $10 \mathrm{~min}$ at the end of each cyclic PCR run. The amplified products were checked on 1\% TBE agarose gels and either purified directly with the Nucleo Spin Extract II kit (Macherey \& Nagel, Germany) or the Blue Matrix PCR/DNA clean up DNA Purification kit (EurX, Poland), respectively. If gel purification was necessary, we used the QIAquick Gel Extraction kit (Qiagen). In some cases it was required to PCR-clone some fragments for better sequencing results. We then used the pGEM-T Easy Vector system (Promega) and selected positive clones by blue-white screening. Plasmid purification was performed with the Quantum Prep Plasmid mini kit (BioRad), according to the manufacturer's protocol.

\section{Sequencing and data assembly}

Initial sequencing of amplified PCR fragments was carried out in the Berlin lab, using a $\mathrm{CEQ}^{\mathrm{mm}} 8000$ capillary sequencer (Beckmann-Coulter, USA) and the CEQ DCTS Quick Start kit (Beckmann-Coulter) according to the standard protocol, except for using half volumes for setup of the sequencing reaction $(10 \mu \mathrm{l})$. Final

Table 2 Primer pairs and annealing temperatures successfully used for primer walking

\begin{tabular}{llc}
\hline Primer Pair & \multicolumn{1}{c}{ Primer Sequence $\left(\mathbf{3}^{\prime}-\mathbf{5}^{\prime}\right)$} & Annealing Temperature $\left({ }^{\circ} \mathbf{C}\right)$ \\
\hline SR 16S-f & CTT ATG TTT TT TTA GTT TGC GAC CTC & 62 \\
SR cob-f & GGG GGA GTG ATT GCT TTG TTG C & 64 \\
SR cox3-f & CAA CAG GGT TTC ACG GAA TAC ACG & 65 \\
SR 16S-r & GAG GTC GCA AAC TAA AAA AAA CAT AAG & 62 \\
SR cobf-rev & TGT TGG AGA TCT AAC AGA ATA AGC AC & 60.1 \\
SR colf-rev & CTT TCT GAG ATA AAA GTA GGT CCT GG & 61.6 \\
\hline
\end{tabular}

Sequences are illustrated from $5^{\prime}$ to $3^{\prime}$ end. 
Table 3 Names, taxonomic classifications and GenBank accession numbers of the species used in our phylogenetic analyses (asterisks point to partial genome data; percental coverage in the final alignment is indicated for these taxa)

\begin{tabular}{|c|c|c|}
\hline Species & Systematic position & GenBank accession number \\
\hline Symsagittifera roscoffensis & Acoela & [GenBank: HM237350] \\
\hline Paratomella rubra*(69\%) & Acoela & [GenBank: AY228758] \\
\hline Nemertoderma westbladii*(35\%) & Nemertodermatida & [GenBank: AY228757] \\
\hline Urechis caupo & Echiura & [GenBank: NC_006379] \\
\hline Myzostoma seymourcollegiorum*(80\%) & Myzostomida & [GenBank: EF506562] \\
\hline Lumbricus terrestris & Annelida - Clitellata & [GenBank: NC_001677] \\
\hline Platynereis dumerilii & Annelida - "Polychaeta" & [GenBank: NC_000931] \\
\hline Microstomum lineare ${ }^{*}(49 \%)$ & Platyhelminthes - Turbellaria & [GenBank: AY228756] \\
\hline Trichobillharzia regenti & Platyhelminthes - Trematoda & [GenBank: NC_009680] \\
\hline Fasciola hepatica & Platyhelminthes - Trematoda & [GenBank: NC_002546] \\
\hline Microcotyle sebastis & Platyhelminthes - Monogenea & [GenBank: NC_009055] \\
\hline Gyrodactylus salaris & Platyhelminthes - Monogenea & [GenBank: NC_008815] \\
\hline Diphyllobothrium latum & Platyhelminthes - Cestoda & [GenBank: NC_008945] \\
\hline Hymenolepis diminuta & Platyhelminthes - Cestoda & [GenBank: NC_002767] \\
\hline Trichinella spiralis & Nematoda & [GenBank: NC_002681] \\
\hline Xiphinema americanum & Nematoda & [GenBank: NC_005928] \\
\hline Caenorhabditis elegans & Nematoda & [GenBank: NC_001328] \\
\hline Brachionus plicatilis (part 1) & Rotifera & [GenBank: NC_010472] \\
\hline Brachionus plicatilis (part 2) & Rotifera & [GenBank:NC_010484] \\
\hline Leptorhynchoides thecatus & Acanthocephala & [GenBank: NC_006892] \\
\hline Epiperipatus biolleyi & Onychophora & [GenBank: NC_009082] \\
\hline Limulus polyphemus & Chelicerata - Xiphosura & [GenBank: NC_003057] \\
\hline Lithobius forficatus & Myriapoda - Chilopoda & [GenBank: NC_002629] \\
\hline Drosophila yakuba & Hexapoda - Pterygota & [GenBank: NC_001322] \\
\hline Triops cancriformis & Crustacea - Phyllopoda & [GenBank: NC_004465] \\
\hline Squilla mantis & Crustacea - Malacostraca & [GenBank: NC_006081] \\
\hline Priapulus caudatus & Priapulida & [GenBank: NC_008557] \\
\hline Lineus viridis & Nemertea & [GenBank: NC_012889] \\
\hline Phoronis psammophila*(98\%) & Phoronida & [GenBank: AY368231] \\
\hline Terebratulina retusa & Brachiopoda & [GenBank: NC_000941] \\
\hline Laqueus rubellus & Brachiopoda & [GenBank: NC_002322] \\
\hline Katharina tunicate & Mollusca - Polyplacophora & [GenBank: NC_001636] \\
\hline Haliotis rubra & Mollusca - Gastropoda & [GenBank: NC_005940] \\
\hline Octopus ocellatus & Mollusca - Cephalopoda & [GenBank: NC_007896] \\
\hline Loxosomella aloxiata & Entoprocta & [GenBank: NC_010432] \\
\hline Flustrellidra hispida & Bryozoa/Ectoprocta & [GenBank: NC_008192] \\
\hline Bugula neritina & Bryozoa/Entoprocta & [GenBank: NC_010197] \\
\hline Paraspadella gotoi & Chaetognatha & [GenBank: NC_006083] \\
\hline Spadella cephaloptera & Chaetognatha & [GenBank: NC_006386] \\
\hline Balanoglossus carnosus & Hemichordata & [GenBank: NC_001887] \\
\hline Branchiostoma floridae & Chordata - Cephalochordata & [GenBank: NC_000834] \\
\hline Myxine glutinosa & Chordata - Craniata & [GenBank: NC_002639] \\
\hline Florometra serratissima & Echinodermata - Crinoidea & [GenBank: NC_001878] \\
\hline Asterias amurensis & Echinodermata - Asteroidea & [GenBank: NC_006665] \\
\hline Cucumaria miniata & Echinodermata - Holothuroidea & [GenBank: NC_005929] \\
\hline Xenoturbella bocki & Xenoturbellida & [GenBank: NC_008556] \\
\hline Oscarella carmela & Porifera - Demospongia & [GenBank: NC_009090] \\
\hline Geodia neptuni & Porifera - Demospongia & [GenBank: NC_006990] \\
\hline Acropora tenuis & Cnidaria - Anthozoa & [GenBank: NC_003522] \\
\hline Aurelia aurita & Cnidaria - Scyphozoa & [GenBank: NC_008446] \\
\hline Trichoplax adhaerens & Placozoa & [GenBank: NC_008151] \\
\hline
\end{tabular}


sequencing was performed by the professional sequencing service of AGOWA (Berlin, Germany). Following sequencing, BLAST programs on the NCBI server were used to determine rRNA- and protein-encoding genes. ClustalW and the cap-contig program, both integrated in BioEdit version 7.0.5 [57], were used for sequence assembly and comparison. The final sequence was compared with previously published mitogenomic sequences of other taxa recovered from GenBank and OGRe [58]. For comparison and evaluation of gene boundaries we built alignments from genes of several metazoan species (predominantly including Platyhelminthes and other Lophotrochozoa, as well as Xenoturbella bocki). In addition, our sequence was compared to the recently published EST data of S. roscoffensis from the NCBI trace archive to get an independent confirmation of gene boundaries. The putative secondary structures of all tRNAs were either detected in a combined approach using tRNAscan-SE [59], ARWEN [60] or by extensive inspection of intergenic regions by eye. The complete $\mathrm{mt}$ genome sequence of $S$. roscoffensis is deposited at the NCBI database with accession number [GenBank: HM237350]. CREx [42] was used to determine common intervals and breakpoint distances in pair wise comparisons of gene orders. AT and GC skew were calculated according to the following formula: $\mathrm{AT}$ skew $=(\mathrm{A}$ $\%-\mathrm{T} \%) /(\mathrm{A} \%+\mathrm{T} \%) ; \mathrm{GC}$ skew $=(\mathrm{G} \%-\mathrm{C} \%) /(\mathrm{G} \%+\mathrm{C} \%)$, as described in [35].

\section{Phylogenetic analysis}

For the phylogenetic analyses we concatenated amino acid alignments from 11 protein-coding genes. We omitted alignments from atp 8 and $n a d 4 l$, as these are the shortest and least conserved genes from the protein-coding set of animal $\mathrm{mt}$ genomes. A total of 60 species was chosen to build the alignments. A detailed overview of the respective taxa and their accession numbers is given in table 3 . The alignment of proteincoding genes was done with MAFFT using the FFT-NSi option [61]. Gblocks ver. 0.91 [62] was used for excluding ambiguously aligned proportions. We used the following settings for the 50 species dataset: minimum number for a conserved position: 26 ; minimum number for a flank position: 26; maximum number of non-conserved positions: 8; minimum length of a block: 10; allowed gap positions: with half. The reduced alignment has a length of 2095 amino acids, which is $42 \%$ of the original alignment (4959 amino acids). The alignment is available from the corresponding author's website http://www.cgae.de. NH-PhyloBayes [63] was used to conduct Bayesian inference with the site-heterogeneous CAT model and the BP option, allowing changes of model settings at "breakpoints" along the tree (empirical optimisation). Four independent MCMC chains were run for each specific alignment. Runs were checked for convergence and stopped when all chains converged to a similar topology. If not, runs were continued up to three weeks on a fast multicore processor unit, allowing for about 10000 sample points per run. Bayesian posterior probabilities (BPP) were calculated from the trees sampled during stationary phase of the different chains.

\section{Additional material}

Additional file 1: Supplemental Figs. S1-3. Gene order comparison with CREX (number of common intervals, breakpoint distances); phylogenetic analysis under exclusion of Acoela and Nemertodermatida; phylogenetic analysis under exclusion of Xenoturbella.

\section{Abbreviations}

atp 6/8: ATPase subunit 6/8 genes; cob: cytochrome b gene; cox 1-3: cytochrome oxidase subunit I-III genes; mtDNA: mitochondrial DNA; nad1-6 and nad4L: NADH dehydrogenase subunit 1-6 and $4 \mathrm{~L}$ genes; rrnS/rrnL: small/ large rRNA subunit genes; rRNA: ribosomal RNA; tRNA: transfer RNA; $\operatorname{trn} X$ : tRNA gene $X$ (' $X$ ' replaces the one-letter amino acid code of the respective tRNA); nt: nucleotides; PCR: polymerase chain reaction.

\section{Acknowledgements}

AM and LP greatly appreciate Thomas Bartolomaeus for his support during this work. AM and LP were supported by German research foundation (DFG), grants BA 1520/10-1,2 (LP); PO 765/4-3 (LP, AM), both from priority programme 1174 "Deep Metazoan Phylogeny"; A short term research stay from AM was supported by DAAD; XB received funding from Europôle Mer, a research consortium on marine science and technology in Brittany http:// www.europolemer.eu/en/; DTJL was supported by NHM/GIA funds. UJ and SB were supported by the Swedish Research council.

\section{Author details}

'Department of Evolutionary Biology and Ecology, University of Bonn, An der Immenburg 1, 53121 Bonn, Germany. 2UPMC-CNRS, FR2424, Station Biologique de Roscoff, Place Georges Teissier, 29680 Roscoff, France. ${ }^{3}$ Department of Invertebrate Zoology, Swedish Museum of Natural History, Box 50007, 10405 Stockholm, Sweden. ${ }^{4}$ Department of Zoology, Natural History Museum, Cromwell Road, London SW7 5BD, UK.

\section{Authors' contributions}

AM did most of the laboratory experiments. XB reared animals and provided helpful EST data. All authors analysed parts of the data and did phylogenetic analyses. All authors discussed results. AM, LP and DTJL wrote substantial parts of the manuscript. All authors read and approved the final manuscript.

Received: 20 May 2010 Accepted: 13 October 2010

Published: 13 October 2010

\section{References}

1. Tyler S, Rieger RM: Functional morphology of musculature in the acoelomate worm, Convoluta pulchra (Plathelminthes). Zoomorphology 1999, 119:127-141.

2. Bourlat SJ, Hejnol A: Acoels. Curr Biol 2009, 19:R279-R280.

3. Ehlers U: Das Phylogenetische System der Plathelminthes Stuttgart, New York: Gustav Fischer 1985.

4. Karling TG, Nilsson AM: Further studies on genus Hypoblepharina Bohmig (Turbellaria, Dalyellioida), with description of $H$. serrifera sp. n. Zoo/ Scr 1974, 3:59-63.

5. Smith JPS, Teyler S, Rieger RM: Is the Turbellaria Polyphyletic. Hydrobiologia 1986, 132:13-21.

6. Haszprunar G: Plathelminthes and Plathelminthomorpha - paraphyletic taxa? J Zool Syst Evol Res 1996, 34:41-47. 
7. Klauser MD, Smith JPS, Tyler S: Ultrastructure of the Frontal Organ in Convoluta and Macrostomum Spp - Significance for Models of the Turbellarian Archetype. Hydrobiologia 1986, 132:47-52.

8. Tekle YI, Raikova OI, Justine JL, Hendelberg J, Jondelius U: Ultrastructural and immunocytochemical investigation of acoel sperms with 9+1 axoneme structure: new sperm characters for unraveling phylogeny in Acoela. Zoomorphology 2007, 126:1-16.

9. Reuter M, Raikova OI, Gustafsson MKS: An endocrine brain? The pattern of FMRF-amide immunoreactivity in Acoela (Plathelminthes). Tissue \& Cell 1998, 30:57-63.

10. Kotikova EA, Raikova Ol: Architectonics of the central nervous system in Acoela, Plathelminthes, and Rotifera. Zh Evol Biokhim Fiziol 2008, 44:83-93.

11. Reuter M, Raikova OI, Jondelius U, Gustafsson MKS, Maule AG, Halton DW: Organisation of the nervous system in the Acoela: an immunocytochemical study. Tissue \& Cell 2001, 33:119-128.

12. Carranza S, Baguñà J, Riutort M: Are the Platyhelminthes a monophyletic primitive group? An assessment using 18S rDNA sequences. Mol Biol Evol 1997, 14:485-497.

13. Litvaitis MK, Rohde K: A molecular test of platyhelminth phylogeny: inferences from partial 285 rDNA sequences. Invertebr Biology 1999, 118:42-56

14. Littlewood DTJ, Rohde K, Clough KA: The interrelationships of all major groups of Platyhelminthes: phylogenetic evidence from morphology and molecules. Biol Journal Linn Soc 1999, 66:75-114.

15. Mallatt J, Craig CW, Yoder MJ: Nearly complete rRNA genes assembled from across the metazoan animals: Effects of more taxa, a structurebased alignment, and paired-sites evolutionary models on phylogeny reconstruction. Mol Phylogenet Evol 2010, 55:1-17.

16. Ruiz-Trillo I, Riutort M, Littlewood DT, Herniou EA, Baguñà J: Acoel flatworms: earliest extant bilaterian Metazoans, not members of Platyhelminthes. Science 1999, 283:1919-1923.

17. Ruiz-Trillo I, Riutort M, Fourcade HM, Baguñà J, Boore JL: Mitochondrial genome data support the basal position of Acoelomorpha and the polyphyly of the Platyhelminthes. Mol Phylogenet Evol 2004, 33:321-332.

18. Baguñà J, Riutort M: The dawn of bilaterian animals: the case of acoelomorph flatworms. Bioessays 2004, 26:1046-1057.

19. Jondelius U, Ruiz-Trillo I, Baguñà J, Riutort M: The Nemertodermatida are basal bilaterians and not members of the Platyhelminthes. Zool Scr 2002, 31:201-215.

20. Wallberg A, Curini-Galletti M, Ahmadzadeh A, Jondelius U: Dismissal of Acoelomorpha: Acoela and Nemertodermatida are separate early bilaterian clades. Zool Scr 2007, 36:509-523.

21. Paps J, Baguñà J, Riutort M: Bilaterian Phylogeny: A Broad Sampling of 13 Nuclear Genes Provides a New Lophotrochozoa Phylogeny and Supports a Paraphyletic Basal Acoelomorpha. Molecular Biology and Evolution 2009, 26:2397-2406.

22. Hejnol A, Martindale MQ: Acoel development indicates the independent evolution of the bilaterian mouth and anus. Nature 2008, 456:382-386.

23. Hejnol A, Martindale MQ: Acoel development supports a simple planulalike urbilaterian. Philos T R Soc B 2008, 363:1493-1501.

24. Moreno E, De Mulder K, Salvenmoser W, Ladurner P, Martinez P: Inferring the ancestral function of the posterior Hox gene within the Bilateria: controlling the maintenance of reproductive structures, the musculature and the nervous system in the acoel flatworm Isodiametra pulchra. Evol Dev 2010, 12:258-266.

25. Hejnol A, Martindale MQ: Coordinated spatial and temporal expression of Hox genes during embryogenesis in the acoel Convolutriloba longifissura. Bmc Biology 2009, 7.

26. Moreno E, Nadal M, Baguñà J, Martinez P: Tracking the origins of the bilaterian Hox patterning system: insights from the acoel flatworm Symsagittifera roscoffensis. Evol Dev 2009, 11:574-581.

27. Martindale MQ, Hejnol A: A developmental perspective: changes in the position of the blastopore during bilaterian evolution. Dev Cell 2009, 17:162-174.

28. Egger B, Steinke D, Tarui H, De Mulder K, Arendt D, Borgonie G, Funayama N, Gschwentner R, Hartenstein V, Hobmayer B, Hooge M, Hrouda M, Ishida S, Kobayashi C, Kuales G, Nishimura O, Pfister D, Rieger R, Salvenmoser W, Smith J, Technau U, Tyler S, Agata K, Salzburger W, Ladurner P: To Be or Not to Be a Flatworm: The Acoel Controversy. Plos One 2009, 4:1-10.
29. Philippe H, Brinkmann H, Martinez P, Riutort M, Baguna J: Acoel Flatworms Are Not Platyhelminthes: Evidence from Phylogenomics. Plos One 2007, 2.

30. Dunn CW, Hejnol A, Matus DQ, Pang K, Browne WE, Smith SA, Seaver E, Rouse GW, Obst M, Edgecombe GD, Sorensen MV, Haddock SH, SchmidtRhaesa A, Okusu A, Kristensen RM, Wheeler WC, Martindale MQ, Giribet G: Broad phylogenomic sampling improves resolution of the animal tree of life. Nature 2008, 452:745-749.

31. Hejnol A, Obst M, Stamatakis A, Ott M, Rouse GW, Edgecombe GD, Martinez P, Baguñà J, Bailly X, Jondelius U, Wiens M, Muller WE, Seaver E, Wheeler WC, Martindale MQ, Giribet G, Dunn CW: Assessing the root of bilaterian animals with scalable phylogenomic methods. Proc Biol Sci 2009, 276:4261-4270

32. Le TH, Blair D, McManus DP: Mitochondrial genomes of parasitic flatworms. Trends Parasitol 2002, 18:206-213.

33. Lavrov DV, Lang BF: Transfer RNA gene recruitment in mitochondrial DNA. Trends Genet 2005, 21:129-133.

34. Wolstenholme DR: Animal mitochondrial DNA: structure and evolution. Int Rev Cytol 1992, 141:173-216.

35. Perna NT, Kocher TD: Patterns of nucleotide composition at fourfold degenerate sites of animal mitochondrial genomes. J Mol Evol 1995, 41:353-358.

36. Hassanin A, Leger N, Deutsch J: Evidence for multiple reversals of asymmetric mutational constraints during the evolution of the mitochondrial genome of metazoa, and consequences for phylogenetic inferences. Syst Biol 2005, 54:277-298.

37. Le TH, Blair D, McManus DP: Complete DNA sequence and gene organization of the mitochondrial genome of the liverfluke, Fasciola hepatica L. (Platyhelminthes; Trematoda). Parasitology 2001, 123:609-621.

38. Bourlat SJ, Juliusdottir T, Lowe CJ, Freeman R, Aronowicz J, Kirschner M, Lander ES, Thorndyke M, Nakano H, Kohn AB, Heyland A, Moroz LL, Copley RR, Telford MJ: Deuterostome phylogeny reveals monophyletic chordates and the new phylum Xenoturbellida. Nature 2006, 444:85-88.

39. Bourlat SJ, Rota-Stabelli O, Lanfear R, Telford MJ: The mitochondrial genome structure of Xenoturbella bocki (phylum Xenoturbellida) is ancestral within the deuterostomes. BMC Evol Biol 2009, 9:107.

40. Perseke M, Hankeln T, Weich B, Fritzsch G, Stadler PF, Israelsson O, Bernhard D, Schlegel M: The mitochondrial DNA of Xenoturbella bocki: genomic architecture and phylogenetic analysis. Theory Biosci 2007, 126:35-42.

41. Lavrov DV, Lang BF: Poriferan mtDNA and animal phylogeny based on mitochondrial gene arrangements. Syst Biol 2005, 54:651-659.

42. Bernt M, Merkle D, Ramsch K, Fritzsch G, Perseke M, Bernhard D, Schlegel M, Stadler PF, Middendorf M: CREx: inferring genomic rearrangements based on common intervals. Bioinformatics 2007 23:2957-2958.

43. Lartillot N, Philippe $\mathrm{H}$ : A Bayesian mixture model for across-site heterogeneities in the amino-acid replacement process. Mol Biol Evol 2004, 21:1095-1109.

44. Lartillot N, Brinkmann H, Philippe H: Suppression of long-branch attraction artefacts in the animal phylogeny using a site-heterogeneous model. BMC Evol Biol 2007, 7(Suppl 1):S4.

45. Blanquart S, Lartillot $\mathrm{N}: \mathrm{A}$ site- and time-heterogeneous model of amino acid replacement. Mol Biol Evol 2008, 25:842-858.

46. Singh TR, Tsagkogeorga G, Delsuc F, Blanquart S, Shenkar N, Loya Y, Douzery EJ, Huchon D: Tunicate mitogenomics and phylogenetics: peculiarities of the Herdmania momus mitochondrial genome and support for the new chordate phylogeny. BMC Genomics 2009, 10:534.

47. Castoe TA, de Koning AP, Kim HM, Gu W, Noonan BP, Naylor G, Jiang ZJ, Parkinson CL, Pollock DD: Evidence for an ancient adaptive episode of convergent molecular evolution. Proc Natl Acad Sci USA 2009, 106:8986-8991.

48. Telford MJ: Xenoturbellida: The Fourth Deuterostome Phylum and the Diet of Worms. Genesis 2008, 46:580-586.

49. Lundin K: The epidermal ciliary rootlets of Xenoturbella bocki (Xenoturbellida) revisited: new support for a possible kinship with the Acoelomorpha (Platyhelminthes). Zool Scr 1998, 27:263-270.

50. Raikova OI, Reuter M, Jondelius U, Gustafsson MKS: The brain of the Nemertodermatida (Platyhelminthes) as revealed by anti-5HT and antiFMRFamide immunostainings. Tissue \& Cell 2000, 32:358-365.

51. Nielsen C: After all: Xenoturbella is an acoelomorph! Evol Dev 2010, 12:243. 
52. Fritzsch G, Boehme MU, Thorndyke M, Nakano $H$, Israelsson O, Stach $T$, Schlegel M, Hankeln T, Stadler PF: PCR survey of Xenoturbella bocki Hox genes. Journal of Experimental Zoology Part B-Molecular and Developmental Evolution 2008, 310B:278-284

53. Le TH, Blair D, Agatsuma T, Humair PF, Campbell NJ, Iwagami M, Littlewood DT, Peacock B, Johnston DA, Bartley J, Rollinson D, Herniou EA, Zarlenga DS, McManus DP: Phylogenies inferred from mitochondrial gene orders-a cautionary tale from the parasitic flatworms. Mol Biol Evol 2000 17:1123-1125

54. Folmer O, Black M, Hoeh W, Lutz R, Vrijenhoek R: DNA primers for amplification of mitochondrial cytochrome c oxidase subunit I from diverse metazoan invertebrates. Mol Mar Biol Biotechnol 1994, 3:294-299.

55. Boore $J$, Brown WM: Mitochondrial genomes of Galathealinum, Helobdella, and Platynereis: sequence and gene arrangement comparisons indicate that Pogonophora is not a phylum and Annelida and Arthropoda are not sister taxa. Mol Biol Evol 2000, 17:87-106.

56. Palumbi SR: What can molecular genetics contribute to marine biogeography? An urchin's tale. J Exp Mar Biol Ecol 1996, 203:75-92.

57. Hall TA: BioEdit a user-friendly biological sequence alignment editor and analysis program for Windows 95/98/NT. Nucleic Acids Symp Ser 1999, 41:95-98.

58. Jameson D, Gibson AP, Hudelot C, Higgs PG: OGRe: a relational database for comparative analysis of mitochondrial genomes. Nucleic Acids Res 2003, 31:202-206.

59. Lowe TM, Eddy SR: tRNAscan-SE: A program for improved detection of transfer RNA genes in genomic sequence. Nucleic Acids Res 1997, 25:955-964.

60. Laslett D, Canbäck B: ARWEN: a program to detect tRNA genes in metazoan mitochondrial nucleotide sequences. Bioinformatics 2008, 24:172-175.

61. Katoh K, Asimenos G, Toh H: Multiple Alignment of DNA Sequences with MAFFT. Meth Mol Biol 2009, 537:39-64.

62. Castresana J: Selection of conserved blocks from multiple alignments for their use in phylogenetic analysis. Mol Biol Evol 2000, 17:540-552.

63. Blanquart S, Lartillot N: A Bayesian compound stochastic process for modeling nonstationary and nonhomogeneous sequence evolution. $\mathrm{Mol}$ Biol Evol 2006, 23:2058-2071.

doi:10.1186/1471-2148-10-309

Cite this article as: Mwinyi et al:: The phylogenetic position of Acoela as revealed by the complete mitochondrial genome of Symsagittifera roscoffensis. BMC Evolutionary Biology 2010 10:309.

\section{Submit your next manuscript to BioMed Central and take full advantage of:}

- Convenient online submission

- Thorough peer review

- No space constraints or color figure charges

- Immediate publication on acceptance

- Inclusion in PubMed, CAS, Scopus and Google Scholar

- Research which is freely available for redistribution

Submit your manuscript at www.biomedcentral.com/submit
Biomed Central 